\title{
Circuitos da Economia na fronteira amapaense: um híbrido de subsistemas para a sua reorganização espacial
}

DOSSIER RIOS E CIDADES

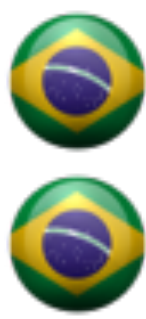

\section{Jadson Luís Rebelo Porto}

Geógrafo, Mestre em Geografia, Doutor em Economia, Pós-doutorado em Desenvolvimento Regional;

Professor do Mestrado em Desenvolvimento Regional e de Planejamento Regional e Urbano da Universidade Federal do Amapá. Macapá [AP] Brasil. <jadsonporto@yahoo.com.br>.

\section{Ivo Marcos Theis}

Doutor em Geografia; Professor Titular da Universidade Regional de Blumenau. Bolsista de Produtividade em Pesquisa do CNPq - Nível 2. Blumenau [SC] Brasil. <theis@furb.br>.

\section{Resumo}

A organização territorial de espaços fronteiriços e a sua (re)formatação para transfronteiriços, em especial as do Estado do Amapá com a Guiana Francesa, necessitam de análises mais profundas quando se insere nos debates do desenvolvimento regional, ao inserir reflexões sobre sua condição fronteiriça, sua organização espacial e reconstruindo sua interação espacial. Serão adotadas as abordagens de Milton Santos, a partir de reflexões sobre as categorias de sistemas de objetos, de normas, de ações, e os circuitos da economia. Este trabalho visa discutir a formatação do circuito econômico da fronteira Amapá-Guiana Francesa a partir das recentes ações econômicas ali estabelecidas, proporcionando novos usos da fronteira e do seu território. Este trabalho subdivide-se em três partes. 0 primeiro apresenta uma reflexão sobre a (des)construção do espaço, o uso do território e a partir do enfoque miltoniano sobre os sistemas de objetos, de normas e de ações; No segundo, discute-se os subsistemas dos circuitos da economia miltoniano (superior e inferior) como agentes (des)estimuladores para a (re)organização do espaço; No terceiro, insere-se a função da fronteira e a busca pela integração territorial; No quarto, debate-se a inserção do Estado do Amapá como uma fronteira tardia.

\section{Palavras-chave}

Fronteira; Circuitos da economia; Amapá; Fronteira tardia amapaense.

\section{Circuits of Economy on Amapa's border: a hybrid of subsystems for its spatial reorganization}

\begin{abstract}
Territorial organization of boundary spaces and its (re)formatting to transboundary, especially those of Amapa State with French Guiana, need deeper analysis when inserted on regional development debates, by inserting reflections about Amapá's border condition, its spatial organization and reconstructing its spatial interaction. Milton Santos's approaches are going to be adopted from reflections about the categories of object, rule and action systems, and economy circuits. This work aims in discussing the economy circuit formatting of Amapa-French Guiana border from recent economy actions established there, providing new use of the border and its territory. This work is subdivided into three parts. The first one presents a reflection about the spatial (de)construction, the use of the territory and, from Milton Santos's focus, a reflection about object, rule and action systems; On the second, Milton Santos's circuit economy subsystems (superior and inferior) are discussed as (un)stimulating agents for space (re)organization; On the third, the border's function and the pursuit for territorial integration are inserted; On the fourth, it is debated about Amapa State's insertion as a late border.
\end{abstract}

\section{Keywords}

Border; Economy circuits; Amapa; Amapa's late border. 


\section{Introdução}

A organização territorial de espaços fronteiriços e a sua reformatação para transfronteiriços necessitam de análises mais profundas quando se insere nos debates do desenvolvimento regional, pois esses espaços e este tema necessitam de discussões multifocal, multiescalar e multidisciplinar. Para as reflexões aqui trabalhadas, serão adotadas as abordagem de Milton Santos, a partir de reflexões sobre as categorias de sistemas de objetos, de normas, de ações, e os circuitos da economia. A partir de então, identificar as suas características e identidades para a (re)formatação da fronteira amazônica, em especial, a do Estado do Amapá.

O transfronteirização entre Amapá e Guiana Francesa é um processo recentemente instalado e representa uma nova articulação entre o Brasil e o Platô das Guianas. Com isso, novos ritmos e uso do seu território começam a ser construídos, seja para se pensar as políticas públicas, seja para se investir recursos privados externos com aval do setor público. Esses comportamentos agiram na: (re)construção de novos usos da fronteira amapaense; reforma de sua condição fronteiriça; (re)organização espacial e; reconstrução sua interação espacial. 0 interesse por este espaço é decorrente de dois fatores: o primeiro, deve-se ao fato desta fronteira se caracterizar como uma fronteira inversa; o segundo, é decorrente desta fronteira ser a maior fronteira da França no cenário mundial.

Este trabalho visa discutir a formatação do circuito econômico da fronteira Amapá-Guiana Francesa. Embora haja registros de interações e relações fronteiriças desde o século XVII neste espaço, as recentes ações econômicas ali estabelecidas tem proporcionado novos usos da fronteira e do seu território.

A construção deste artigo é composta por três tópicos: 0 primeiro apresenta uma reflexão sobre a (des)construção do espaço, o uso do território; No segundo, discute-se os subsistemas dos circuitos da economia miltoniano (superior e inferior) como agentes (des)estimuladores para a (re)organização do espaço; No Terceiro, insere-se a função da fronteira e a busca pela integração territorial; No quarto, debate-se a inserção do Estado do Amapá como uma fronteira tardia.

\section{Da (des)construção do espaço ao uso do território}

A configuração da fronteira e a maneira como ela é (des)usada, tem sido alvo de várias discussões nas mais variadas áreas das ciências. A reflexões aqui expostas serão embasadas nas propostas lançadas por Milton Santos (1994; 1996 e 2004), nas seguintes categoriais: os sistemas de normas e de objetos; o uso do território e; os circuitos da economia.

Souza, (2005, p. 253), ao resgatar a o artigo de Milton Santos (1994), ressalta que o território usado deve ser compreendido como uma mediação entre o mundo e a sociedade nacional e local. A autora ressalta que território usado é uma categoria integradora por excelência e que, especialmente no planejamento, vem definitivamente terminar com as falsas premissas da possibilidade da gestão intersetorial à partir da justaposição do setorial na elaboração dos planos.

Para Santos (1994), é o uso do território, e não o território em si mesmo, que faz dele objeto da análise social. Seu entendimento é fundamental para afastar o risco de alienação, o risco da perda do sentido da existência individual e coletiva, o risco de renúncia ao futuro. Com isso, a inserção de novas construções espaciais e funcionamento do território, tendo por base, esta nova maneira de se analisar, pode ser muito bem adotada para explicar as horizontalidades e as verticalidades pelas quais as dinâmicas que a fronteira brasileira vem passando desde a década de 1990.

Outro aspecto a ser levantado quando se dialoga fronteira e novos usos do território, diz respeito à dialética espaço-tempo (SANTOS, 1996). Saquet (2002, p. 11), ao resgatar as reflexões miltonianas sobre esta dialética, enaltece "que cada momento histórico tem seu tempo e seu espaço e cada espaço tem seu tempo, resultado do encontro dos eixos do tempo histórico e do tempo 
das coexistências". Com isso, reforça-se a necessidade de se observar a fronteira com outros olhos, não como borda, periferia ou limite, pois o tempo de sua construção, de sua organização, de suas dinâmicas são distintas de qualquer outro espaço de uma nação.

À medida em que a fronteira se insere, ora com mais profundidade, ora com mais superficialidade no circuito internacional, ela pode ser analisada como porta de entrada de um país, como também pode ser a última a ser alcançada. Pode ser analisada como uma rota de passagem à medida em que inte(g)rações espaciais sejam mais estimulados (como acontece em várias fronteiras européias quando foi criada a União Européia).

Outras duas categorias abordada por Santos (1996, p. 50) são os elementos fixos e fluxos. A interação desses expressam a realidade geográfica, principalmente quando o autor considera que atualmente os fixos são cada vez mais artificiais e os fluxos mais diversos, amplos, numerosos e rápidos. Considerando que as técnicas e tecnologias para instalação de fixos não são as mesmas disponíveis para todos e para a densidade de velocidade e fluidez dos fluxos também não são nas mesmas condições nos espaços, a dialética espaço-tempo afeta nas dinâmicas, nas (des)configurações e nas suas (des)construções territoriais.

O que é fundamental entender na obra miltoniana é o espaço como um conjunto [...]

[...] "indissociável de sistemas de objetos e sistemas de ação, solidário e contraditório (op. cit. p. 51). Para o autor, "os sistemas de objetos condicionam a forma como se dão as ações e, de outro lado, o sistema de ações leva à criação de objetos novos ou se realiza sobre objetos preexistentes. É assim que o espaço encontra a sua dinâmica e se transforma" (p. 52).

Ao inserir a fronteira nesta discussão, sugere-se, aqui que medida que a fronteira é ocupada, (re)constrói-se seus sistemas de objetos, (re)faz-se seus sistemas de ações, (re)cria-se seus sistemas de normas e, por fim (re)inventa-se o território lindeiro.

\section{Subsistemas dos circuitos da economia para os processos econômicos e de organização do espaço}

Santos (2004) ao elaborar uma abordagem teórica da urbanização em países subdesenvolvidos, elabora uma reflexão que chamou de "circuitos da economia urbana dos países subdesenvolvidos". Esses circuitos são compostos por dois subsistemas: o superior e o inferior. Enquanto o primeiro é definido pela sua forma de organização, o segundo é um produto da modernização e que está em processo de transformação e adaptação permanente (p. 39). Ou seja, o que está em jogo são: comportamento e uso do território; o conjunto de atividades realizadas em certo contexto e; o setor da população envolvida essencialmente pela atividade e pelo consumo.

Para o autor (p. 32) a história, a formação e a transformação dos espaços periféricos, confundese com a história dos países-pólos, que os identificou como "espaços derivados", e que dependem de dois fatores: 1) o momento da intervenção das primeiras forças externas; e 2) os impactos sucessivos de outras modernizações.

Sobre o circuito superior, Santos (2004, p. 22) afirma que este subsistema [...]

[...] "originou-se diretamente da modernização tecnológica e seus elementos mais
representativos hoje são os monopólios. O essencial de suas relações ocorre fora da
cidade e da região que os abrigam e tem por cenário o país ou o exterior".

Neste sentido, para atender tais demandas, o autor assim identifica os elementos que constituem este circuito (op. cit., p.40): Bancos, comércio e indústria de exportação, indústria urbana moderna, serviços modernos, atacadistas e transportadores. 
Ainda na explicação e da construção desse circuito, Santos (2004, p. 43-48) indica uma série de características e, para atender aos objetivos deste artigo ,salientam-se as seguintes: Utiliza uma tecnologia importada e de alto nível, uma tecnologia de "capital intensivo", imitativo; Os capitais são volumosos em relação à tecnologia utilizada; Emprega um número importante de estrangeiros, variável segundo o grau de industrialização e e modernização do país; Seus preços são geralmente fixos, onde o limite inferior não pode estar muito abaixo dos preços de mercado, sob pena de colocar em risco o futuro de firma, e as manipulações dos preço supões uma margem de lucro contabilizável por longos prazos; Acumula capitais indispensáveis à continuidade das atividades e sua renovação em função dos progressos técnicos; 0 lucro corresponde ao volume de produção e não por unidade; Quanto às atividades: dispõem do crédito bancário; seus custos fixos importantes aumentam com o porte da firma para cada lugar e ramo de fabricação; usufruem direta ou indiretamente da ajuda governamental; tende a controlar a economia por inteiro; aquelas realizadas localmente vão integra-se numa outra cidade de nível superior, no país ou no exterior; 0 funcionamento baseia-se nas necessidades de uma produção "capital intensivo" local ou exógena e; Os elementos de sua articulação serão buscados fora da cidade e de sua região.

Tais características são muito presentes quando identificam-se os investimentos efetivados pelo grande capital internacional na Amazônia, principalmente na exploração de suas commodities, em especial na exploração da borracha (1850-1912) e no processo industrial de extração mineral (pós-1950) ${ }^{1}$; bem como, à medida que a Amazônia se integrava ao mercado nacional e internacional no pós-1970, recebendo novas plantas industriais. A partir de então, conexões e interações foram criados, construídos e articulados, acionando a região amazônica em diversos setores da economia (inter)nacionais.

Quanto ao Circuito inferior, Santos (op. cit., p. 22) identifica que este subsistema é "formado de atividades de pequena dimensão e interessado principalmente às populações pobres, é bem enraizado e mantém relações privilegiadas com sua região". Para o autor, este é um elemento indispensável à apreensão da realidade urbana e para encontrar medidas para atribuir uma produtividade mais elevada, garantir um crescimento sustentado e conservar sua função de fornecedor de empregos. Os elementos que integram este circuito são: formas de fabricação não-capital intensivo, serviços não modernos-fornecidos 'à varejo' e pelo comércio não moderno e de pequena dimensão (p. 40).

Ao explicar e construir as orientações deste circuito, Santos (2004, p. 43-48) indica uma série de características e, para atender aos objetivos deste artigo salientam-se as seguintes: Utiliza 'trabalho intensivo' e frequentemente local ou localmente adaptada ou recriada, com um potencial de criação considerável; 0 contrato empregatício assume a forma de acordo pessoal entre patrão e empregado; a média de ocupados por unidade de produção é baixa, mas o número total de pessoas ocupadas é considerável; Os preços regateados, pechinchados, são regras, e as margens de oscilação dos preços ão muito importantes; 0 prazo curto é o que prevalece; A acumulação de capital não se constitui a primeira preocupação, ou não há tal preocupação. Trata-se de sobreviver e assegurar a vida cotidiana da família, bem como tomar parte de certas formas de consumo particulares à vida moderna; 0 resultado total do controle de preços neste subsistema é pequeno e a margem de lucro por unidade é elevada devido ao grande número de intermediários entre o fornecedor e o consumidor final; Sua integração ocorre na escala local; Os elementos de sua articulação encontram-se na cidade e sua região; No que tange às suas atividades: são baseadas simultaneamente no crédito e no dinheiro líquido, sendo o crédito com uma larga porcentagem de ser pessoal direto, indispensável para o trabalho das pessoas sem possibilidades de acumular; Tanto no comércio quanto na fabricação, trabalham com pequenas quantidades; Aquelas com 'trabalho intensivo' utilizam capitais reduzidos e podem dispensar uma organização burocrática; A reutilização de bens duráveis é uma das suas bases; Não dispõem de apoio governamental e frequentemente são perseguidas; Não necessita de um overhead capital para sua instalação; Tende a ser controlado, subordinado, dependente;

\footnotetext{
${ }^{1}$ O Amapá foi um dos precursores da extração industrial de minérios, quando iniciou o processo de extração manganesífera na década de 1950. Vide Porto (2003).
} 
Este circuito é bem perceptível nas articulações da economia local amazônica, onde ribeirinhos interagem com seu espaço e seus produtos produzidos com as cidades ribeirinhas. Várias obras foram escritas na Amazônia sobre a relação homem-rio-economia local, contudo, destaques sejam feitos à obra de Leandro Tocantins, intitulada "O rio Comanda a vida", que retrata esta convivência. Escrita na década de 1950, é considerada até hoje um clássico entre os trabalhos sobre a região amazônica, e oferece subsídios sobre a paisagem amazônica da várzea, o modo de vida, os costumes e as características do homem amazônico.

\section{Fronteiras e busca pela integração territorial}

As discussões sobre fronteira são muito presentes na literatura de geopolítica, geografia política, ciências políticas, economia, dentre outras ciências. Para melhor orientar nossas discussões, adotar-se-á as observações de Silva (2013), que assim distingue fronteiras e limites. Enquanto a fronteira é um perímetro instaurado por um poder político, cujo interesse e ações são o de se afirmar e se distinguir de outras entidades territoriais igualmente soberanas; o limite, é a marca divisória de dois sistemas políticos soberanos.

Este autor (op. cit.) elabora uma profunda leitura sobre o o tema fronteira e identifica vários autores que abordam o assunto no cenário internacional no pós-1980, apresentando autores que pressupunham a emergência de um novo mundo "sem fronteiras" (a partir do qual as barreiras simbólicas e físicas tornar-se-iam insignificantes); um certo reforço no controle e proteção de diferentes fronteiras; e o mito de abolição das fronteiras-limite.

Para o caso brasileiro, destaques devem ser feitos aos trabalhos realizados pelo grupo RETIS/UFRJ, LABETER/UFRGS e OBFRON/UNIFAP, que rediscutem própria à noção de limite ou divisória internacional, para uma concepção de área ou região de fronteira, tendo por base em suas reflexões as propostas lançadas por Brasil (2005), ao introduzir a distinção relevante entre "faixa e zona de fronteira".

A faixa de fronteira brasileira é normatizada pela a Lei Ordinária no 6.634/1979, que define um espaço de faixa de $150 \mathrm{~km}$ a partir da linha de lindeira. Esta Lei também preconiza que toda vez que existir interesse para a Segurança Nacional, a união poderá concorrer com o custo, ou parte deste, para a construção de obras públicas a cargo dos municípios total ou parcialmente abrangidos pela Faixa de Fronteira.

A zona de fronteira, por sua vez, é composta por 'faixas' territoriais de cada lado do limite internacional, sendo sua extensão geograficamente limitada a algumas dezenas de quilômetros a ambos os lados da linde.

Um aspecto fundamental para se entender as dinâmicas que existem nas fronteiras, diz respeito ao que Perkmann e Sum (2002) apud Silva (2013) chamaram de "estratégias territoriais sobre zonas de fronteira", as quais são conectadas a uma série de grandes tendências que têm afetado o status dos limites nacionais nos últimos anos, tais como: o crescimento de atividades econômicas transfronteiriças através do aumento do movimento de bens, serviços e pessoas; transferência de poderes específicos do Estado, ou seja, a passagem de uma concepção unidimensional à multidimensionalidade do poder; e o fim da Guerra Fria e a tendência à integração e cooperação transfronteiriça.

Com isso, as mudanças estruturais modificaram as estratégias territoriais para o desenvolvimento das zonas de fronteira em três aspectos principais (SILVA, 2013): a permeabilidade crescente das fronteiras abriu o espaço para uma variedade de transações que podem produzir configurações transnacionais mais ou menos duráveis, o que vai depender do jogo de poder nas articulações transfronteiriças; o movimento das capacidades do estado previamente exercitadas no nível nacional em direção a autoridades supranacionais e subnacionais tem alterado a posição anterior de Estados nacionais como os recipientes únicos do poder da administração pública e; o fim da 
Guerra Fria incentivou novos esforços na transformação econômica nas fronteiras políticas.

Quanto à interação entre os estados territoriais na zona de fronteira, esta se expressa frequentemente através da vinculação social e cultural, adotando-se reciprocamente usos, costumes, valores e expressões idiomáticas que são próprias e distintivas das cidades que, mesmo separadas por um limite estabelecido, criam um lócus de interação próprio, só perceptível naquele espaço geográfico (BRASIL, 2005).

Serão aqui adotadas o entendimento de Silva (2013), que defende que tanto as zonas quanto as faixas de fronteira, estão diretamente ligadas com o perfil funcional das fronteiras. Por este motivo, a integração física como questão central do interesse nacional de vários países, atribui às suas fronteiras, zonas e faixas, um novo papel estratégico. Estes espaços geográficos constituem-se pontos de interpenetração, tornando as relações transfronteiriças um tema prioritário das relações internacionais. Em tal contexto, a cooperação transfronteiriça foi e ainda é uma estratégia para explorar oportunidades de desenvolvimento regional.

À medida em que as fronteiras se tornam cada vez mais interativas e integradas, percebe-se o desenvolvimento de uma sociedade em movimento mais ou menos marginal, muitas vezes conquistadora e outras vezes na defensiva; e podem também caracterizar-se por distintos gradientes de abertura para a circulação de pessoas e bens de um lado ao outro. Ou seja, à medida em que sistemas de engenharia são construídos para garantir maior intensidade e fluidez na fronteira, tornando-a transfronteiriça, com a construção de rodovias, pontes, túneis, as relações extrapolam o entorno onde tais são afetados, seja estimulando novos ritmos e dinâmicas territoriais, seja reorganizando novas dinâmicas territoriais. Des-re-territorializando a fronteira.

Para entender melhor a dinâmica lindeira, Silva (2013) identifica dois efeitos que ocorrem na fronteira capazes de (re)organizar o (des)uso do território fronteiriço, suas funções e a sua construção para ações transfronteiriças: o efeito-barreira e o efeito-cooperação. Sobre barreira, o autor a define como qualquer condição ou ação que impede ou restringe a livre circulação e interação de pessoas, capitais, produtos, serviços e ideias. No que diz respeito à cooperação, atua-se na efetiva articulação entre duas áreas vizinhas de países soberanos e abrange todas as nuances da vida diária e o desenvolvimento de programas conjuntos, de prioridades e de ações. A cooperação pretende, por um lado, atenuar a ausência de quadros jurídicos e de circuitos financeiros pertinentes nas zonas de fronteira e, por outro, tornar estas áreas em lugares de oportunidade e de criatividade.

Por fim, para o autor (op. cit.) as relações transfronteiriças podem assumir formas muito distintas, segundo o grau de permeabilidade dos limites e o peso da política nacional, os acordos interestatais e as iniciativas regionais que as alimentam e estimulam. A integração transfronteiriça pode estar guiada pelo mercado e basear-se na proliferação de relações econômicas e sociais ou pode depender da política e apresentar-se como construção de relações de cooperação entre autoridades públicas que compartem alguns interesses como por exemplo de enfrentar problemas ambientais comuns ou criar espaços econômicos transfronteiriços. Essas relações acabam por efetivar 7 etapas para se consolidar uma cooperação transfronteiriça, que vão desde o contato inicial, perpassando por níveis como atração, interação, transação e relacionamento, até o efetivo sucesso (HOUTUM, 1998, apud SILVA, 2013). Para o caso amapaense, Porto (2010a) entende que este se encontra no estágio de interação, ainda incipente.

Grimson (2003, p. 17), analisa as fronteiras como "os regimes de movimentos materiais e simbólicos que através delas incluem uma série de relações econômicas, políticas, sociais e culturais". Porém, seus sentidos são decorrentes da conjunção dos seguintes elementos formadores: território: população, regimes de fluxos e de outras relações sociohistóricas (op. cit., p. 17).

Com isso, o autor sugere o conceito de fronteirização (op. cit., p. 17), cuja ênfase sociocultural indica que [...] 
"a fronteira nunca é um dado fixo, mas um objeto inacabado e instável. Um objeto disputado de diversas formas. Um objeto que como produtos histórico de ação humana pode ser e é, reestruturado e resignificado " (GRIMSON, 2003).

A partir deste foco, Porto (2010a) entende que esta ênfase sociocultural também estabelece a condição fronteiriça como uma construção histórica, social, econômica e politicamente estabelecidas pelas suas relações externas, cujas manifestações locais se expressam pelas reproduções indicadas e orientadas pelo capital externo. Por ser um produto historicamente construído, reestruturado, resignificado, a condição fronteiriça é constantemente (re)inventada. Ou seja, a cada momento histórico, é refeita por ser social e politicamente estabelecida. No contexto social, pode ser percebida como um espaço de diálogo e/ou de conflitos.

Considerando, então a recente articulação entre Amapá e Guiana Francesa, construção histórica e social da condição fronteiriça amapaense tem se caracterizado como um efeito-barreira nesta nova etapa dos novos usos deste território. 0 prof. Manoel Pinto (2011) relata conflitos entre brasileiros e franceses na Guiana Francesa, e esses conflitos tem servido de barreiras para o não avanço de acordo diplomáticos entre Brasil e França.

A condição fronteiriça também possibilita conflitos entre o tradicional e o moderno; garante ações para a (re)organização espacial e não estipula atos para a sua execução. Estabelece oportunidades, tolerâncias e flexibilidades de uso do território. As novas modalidades deste uso, historicamente construídas, refletem na construção e configuração do espaço local, que dinamizam suas articulações nas diversas escalas espaciais.

Com essas características, percebe-se que o contato existente na fronteira entre o local e o internacional impõe um dinamismo próprio a este espaço; exigindo dos seus atores posturas que, em diversos momentos, são conflitantes às determinações legais, mas que são executadas devido a diversos interesses que esses atores se disponibilizam a executar ou conquistar.

Os conflitos legais necessariamente indicam a ilegalidade de ações, mas, em muitos casos, na inexistência de um arcabouço de normas direcionadas seja às especificidades locais que a fronteira possui, seja às relações diplomáticas de um espaço ainda considerado como fronteira-barreira. Entretanto, considerando que nada é fixo no espaço, no território e, consequentemente, na fronteira, as redes construídas no sistema-mundo e as funções da fronteira construídas estimulam a desconstrução dos efeito-barreira histórico, político ou economicamente instalados na fronteira para a construção de efeito-cooperação, o que deve ser ressaltado para a construção de uma fronteira tardia.

\section{A formação do espaço amapaense e a reformatação da fronteira}

Três discussões devem ser tomadas quanto à formação da fronteira amapaense: a formação histórica; a inserção do espaço amapaense na economia mundo e; a passagem do uso do território fronteiriço para transfronteiriço (PORTO, 2003; 2007; 2010a; 2010b; 2012; PORTO; SANTOS, 2012; PORTO; SILVA, 2009; PORTO; SUPERTI; SILVA, 2013; PORTO; SUPERTI; TOSTES; SOTTA, 2011). As análises aqui apresentadas terão como ponto de partida a reformatação da fronteira amapaense a partir da instalação dos Territórios Federais no Brasil2 ${ }^{2}$. Estes entes federativos inexistiam nas suas configurações jurídicas brasileiras até a Constituição de 1934.

A primeira experiência brasileira dos Territórios Federais ocorreu com o atual Estado do Acre (1904), cujo modelo seria utilizado para a criação de novos territórios federais na fronteira brasileira. Os outros Territórios (Fernando de Noronha, Amapá, Rio Branco, Guaporé, Ponta Porá

\footnotetext{
${ }^{2}$ Segundo Jacques (1977, p. 188) a expectativa dos Territórios Federais era para atuar "como núcleos de civilização (...), prestar grandes serviços ao país não só em assunto de defesa nacional, como também em matéria econômica e social". Sobre os Territórios Federais, vide Medeiros (1944; 1946); Temer (1975); Mayer (1976); Freitas (1991) e; Porto (2003).
} 
e Iguaçu) foram instalados na década de 1940, sob as orientações da Constituição de 1937, que trouxe no seu art. 4o a previsão de criação de Territórios Federais em razão de interesse da defesa nacional, com atuação direta da União. Com exceção do Acre, incorporado ao Brasil a partir de aquisição de parte do território boliviano, os demais Territórios Federais foram criados por desmembramento de Unidades Federativas brasileiras.

A atual Constituição Brasileira, ainda reconhece a figura dos Territórios Federais na configuração territorial do Brasil, e muitas propostas desses entes foram sugeridas no Congresso $\mathrm{Nacional}^{3}$ (a exemplo dos Territórios Federais do Marajó, do Oiapoque, Rio Branco e Alto Solimões), mas ainda não foram acatados pelo plenário.

Embora a experiência desses Territórios no Brasil perdurasse por 84 anos (1904-1988), não foi possível estabelecer uma visão precisa sobre o que significou esta experiência para a organização espacial da região e, muito menos, sobre as suas atuações no federalismo brasileiro (PORTO, 2003). Mas ficou claro que estes Territórios eram "Estados em embrião" (FERREIRA FILHO, 1975, p. 57) e que serviram como instrumentos de indução à organização do espaço econômico regional sob a tutela do governo federal. Este, por sua vez, destinou recursos e investimentos públicos na instalação de infraestrutura, a fim de criar condições de acesso às economias externas e materializar as condições de se ampliar as vantagens competitivas regionais.

Quanto ao caso do Território Federal do Amapá, as ações de atuação do capital internacional na exploração dos recursos notadamente minerais amapaenses, esta além de atrair um excedente populacional, técnicas e tecnologias modernas e industriais foram incorporadas. Configurando, então, uma configuração territorial e urbana nova e um ritmo novo de produção. Esta condição se encaixa nas característica de Circuito Superior, pois as empresas que exploraram esses minérios situaram-se no rol das 100 empresas maiores do setor no cenário nacional (PORTO, 2003). Em outros termos, inventaram-se dinâmicas territoriais novas (PORTO, 2010c). Para o funcionamento do grande capital em terras amapaenses, viabilizaram-se ajustes espaciais e sistemas de engenharia ${ }^{4}$ a fim de se inventar uma funcionalidade e/ou uma vocação para o Amapá.

Em Abril de 2013, ocorreu a queda do barranco onde se encontra o porto da mineradora Anglo American, no Município de Santana, que exporta minério de ferro oriundo do Município de Pedra Branca do Amapari (AP). Este porto foi construído na década de 1950, para exportação de manganês vindo de Serra do Navio (AP), localizado a $190 \mathrm{~km}$ de distância deste porto. Ambos minérios são/foram escoados por uma linha ferroviária ligando mina ao porto.

Com o sistema nodal ferrovia/porto afetado (por consequência a principal atuação do circuito superior amapaense) e enquanto o porto de escoamento mineral não for construído, haverá mudanças nos ritmos das dinâmicas econômicas do Estado, principalmente nos municípios de Serra do Navio, Pedra Branca do Amapari e de Santana. Como um porto sexagenário, este sistema de engenharia estava por demais amadurecido, e super usado, necessitando de melhorias estruturais. Com o sinistro de 2013, está a oportunidade de construir (não reconstruir) um porto moderno, competitivo, revendo o Plano Diretor do município de Santana (que não aborda a questão portuária). Neste sentido, invenções modernas podem ser adotadas para novos usos do território santanense.

Um outro aspecto da configuração espacial amapaense dizem respeito à criação e à gestão territorial ambiental de grandes Unidades de Conservação (UC) e de Terras Indígenas (TI). Todas elas foram criadas no âmbito do Governo Federal, sem a participação da população e de gestores locais, consolidando a construção exógena da fronteira. Atualmente, o Amapá possui $72 \%$ de seu território com algum grau de restrição institucional de uso e grande parte de suas gestões estão no

\footnotetext{
${ }^{3}$ Vide Ribeiro (1996); Cavalcanti (2002); Rocha (2001); Brasileiro (2003).

${ }^{4}$ Precisamente, rodovias, ferrovia, ampliação portuária, balizamento do rio amazonas, company towns, usina hidrelétrica, incentivos fiscais, dentre outros.
}

PORTO, J.L.R.; THEIS, I.M. Circuitos da Economia na fronteira amapaense: um híbrido de subsistemas para a sua reorganização espacial. Labor \& Engenho, Campinas [SP] Brasil, v.9, n.2, p.101-114, abr./jun. 2015.

$<$ http://www.conpadre.org $>$. 
âmbito federal. Acrescente-se às terras federais, aquelas destinadas à reforma agrária (INCRA) e área de segurança nacional (faixa de fronteira). Com isto, inventaram-se espaços com "restrição de uso do território", forçando aqueles espaços sem restrições de uso a serem especulados, reinventados, reusados, reorganizados com maior intensidade e frequência. Hoje, o Amapá abriga em seu território 19 UC. Destas, 12 estão sob a gestão do governo federal, cinco estão sob gestão do governo estadual, e duas sob a gestão do governo municipal.

Outra dinâmica na fronteira que está em processo de revisão, diz respeito ao que Silva (2008) identificou de "novos usos da fronteira". Os fatores que nela tem contribuído para tais dinâmicas tem sido construídos após década de 1990 pelas seguintes ações (PORTO; SUPERTI; SILVA, 2013): Criação e instalação Unidades de conservação ocupando grandes extensões do território amapaense; A criação da Área de Livre Comércio Macapá/Santana5; 0 envolvimento do Amapá em políticas econômicas internacionais mediante programas infra-estruturais de grande porte (IIRSA e INTERREG III e IV / PO Amazonie ${ }^{6}$ ); A assinatura do Acordo-Quadro entre Brasil-França e as consequências deste acordo no espaço amapaense (Pavimentação da Rodovia BR-156 entre Macapá e Oiapoque; A construção da ponte binacional no rio Oiapoque: os ensaios de cooperação entre AmapáGuiana Francesa; a construção e pavimentação da rodovia entre Saint-George e Caiena; a pavimentação da rodovia entre Macapá e Oiapoque) e; a retomada da mineração após 2004.

Com isso, o Século XXI inicia com esta região integrada e conectada ao cenário internacional, recebendo investimentos para se tornar mais competitiva. E o que a torna fortemente competitiva é a sua biodiversidade e os recursos minerais ali encontrados. Por isso é que se deve repensar o enfoque da fronteira como efeito-barreira. Pois, as novas articulações fronteiriças ensaiadas na fronteira amapaense após a década de 1990, tem se construído ainda em processo de interação, embasada em expectativas e construção tardia. Pois foi somente no início do século XXI que as relações entre Amapá e Guiana Francesa quando ocorreram a transição de relações fronteiriças para transfronteiriças e; a construção de novas políticas de relacionamento Brasil/França, bem como seus reflexos nos demais países localizados no norte da América do Sul.

Ao inserir a Guiana Francesa nas análises sobre a fronteira amapaense, Porto e Santos (2012), entendem que embora esta não se encontre no continente europeu, recebe todas as dinâmicas e diretrizes territoriais européias, pela União Europeia ${ }^{7}$. No Brasil, o único ponto de contato entre essas políticas de Integração localiza-se no município de Oiapoque, condição é estratégica para o Estado do Amapá e para o Brasil. Esta nova configuração territorial rodoviária possui construções espaciais e demográficas distintas. Dentre as observações feitas, verifica-se a mudança de comportamento demográfico sobre o eixo rodoviário da BR-156, exposto no Gráfico da Figura $1^{8}$.

\footnotetext{
${ }^{5}$ A ALCMS representou a possibilidade, da "abertura de um leque de oportunidades e perspectivas de negócios para a economia do Estado, tendo em vista as vantagens oferecidas pelos incentivos fiscais federais constantes do Decreto n. 517 de 1992, que regulamentou a ALCMS" (SILVA; PORTO, 2005, p. 4-5).

6 Os INTERREG III e IV, visam promover a coesão econômica e social das regiões ultraperiféricas através de financiamentos do Fundo Europeu de Desenvolvimento Regional (FEDER) para o período de 2000/2006 e 2007/2013, respectivamente. Os objetivos prosseguidos têm como finalidade, numa primeira fase, reduzir o déficit de acessibilidade dessas regiões não só em relação ao continente europeu como também entre as regiões ultraperiféricas e no interior do respectivo território e, numa segunda fase, apoiar a competitividade das suas empresas. Para o INTERREG IV, a UE disponibilizou recursos financeiros que visam consolidar a coesão social e econômica através de apoio a projetos e atividades em três eixos: 1) projetos transfronteiriços; 2) projetos transnacionais e 3) projetos inter-regionais (CEM, 2005; CE, 2010).
}

\footnotetext{
${ }^{7}$ Segundo Fortuna (2009), "a geografia econômica da União Europeia ultrapassou os limites do continente europeu a partir do momento em que a França incluiu os seus departamentos ultramarinos (dentre eles, a Guiana-Francesa) como parte integrante do processo de integração da União", no início da década de 1990.

${ }^{8}$ Para a elaboração deste gráfico , calculou-se o total da população por município por onde a rodovia BR-156 passa, exceto as populações de Macapá e Santana. No trecho Norte, a rodovia passa pelos seguintes municípios amapaenses: Ferreira Gomes, Porto Grande, Pracuúba, Tartarugalzinho, Amapá, Calçoene e Oiapoque. No trecho Sul, Mazagão, Laranjal do Jari e Vitória do Jari.
}

PORTO, J.L.R.; THEIS, I.M. Circuitos da Economia na fronteira amapaense: um híbrido de subsistemas para a sua 


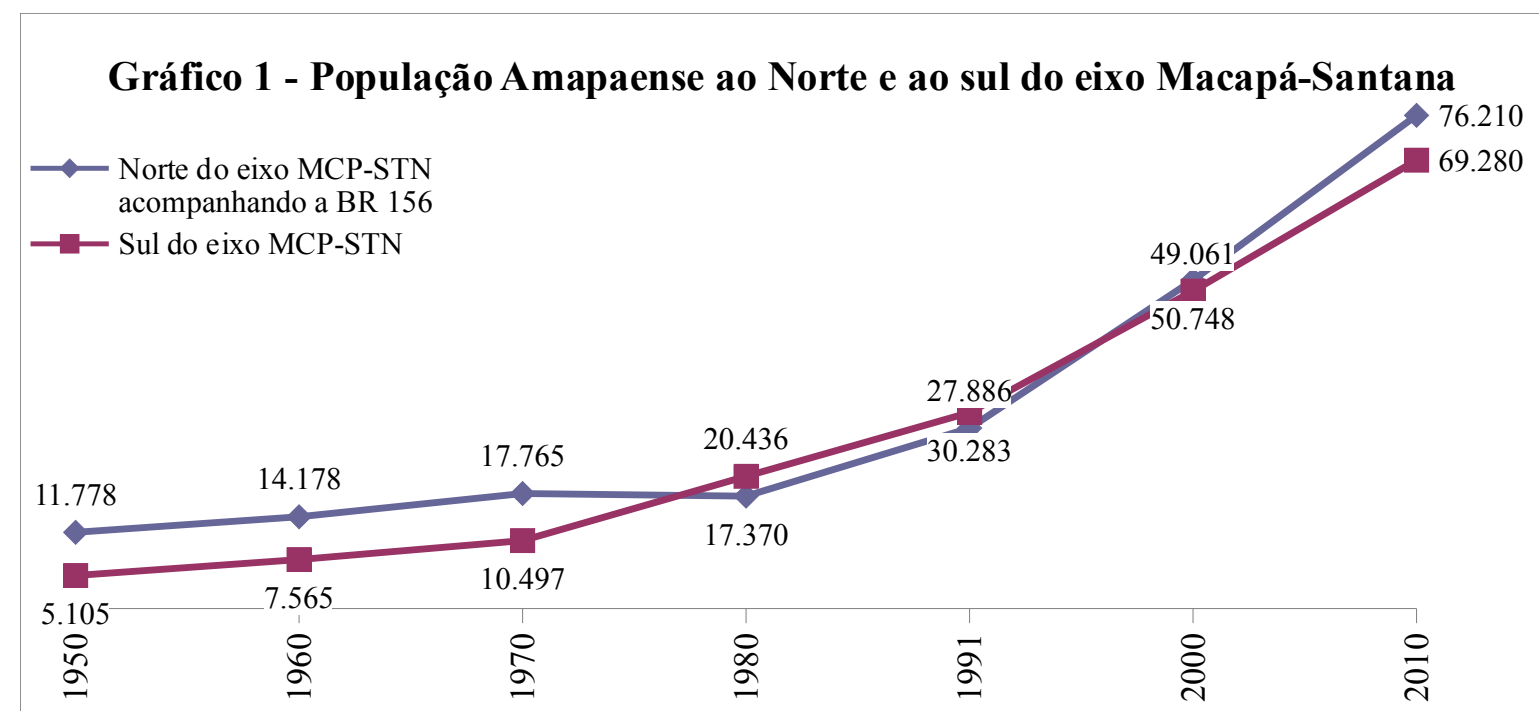

Figura 1. Curvas de crescimento da População Amapaense ao norte e ao sul do eixo Macapá-Santana, de 1950 a 2010.

No período 1950-2010, há dois momentos de intercessão no comportamento demográfico que precisam ser explicados. 0 primeiro cruzamento, indicando o eixo sul sendo superior ao eixo norte, decorre da instalação do Complexo Industrial do Jari, às margens do rio Jari, no município de Almerim (PA). Vale ressaltar que até a segunda metade da década de 1980, o eixo sul desta rodovia não estava pronta. 0 acesso dava-se via hidroviária (Rio Amazonas e rio Jari). 0 segundo cruzamento, na década de 1990, é explicado pela movimentação de brasileiros em busca de ouro na região da fronteira tanto do lado brasileiro, quanto francês.

Observe-se, também a contemporaneidade do movimento pela criação do bloco da União Européia (1992), sendo a Guiana Francesa inserida nesta dinâmica, atraindo brasileiros por melhores condições econômicas.

No primeiro decênio do século XXI, percebe-se um direcionamento da movimentação demográfica em direção à fronteira norte. Este comportamento é explicado pelas obras de pavimentação da BR 156 no trecho Macapá-Oiapoque e pela construção da ponte binacional, como também, pelas expectativas criadas por uma integração Brasil/França ou Mercosul/ União Européia.

A BR-156, integrante do corredor da fronteira Norte, é a espinha dorsal dos transportes amapaenses, cuja pavimentação na porção Norte (entre Macapá e Oiapoque), tem por uma de suas finalidades interligar fisicamente o Brasil aos países vizinhos da região Norte (Guiana Francesa / França, Suriname e Guiana) por meio de um conjunto de infraestruturas que inclui de forma determinante a rodovia Tranguianense, que trata-se na verdade de um conjunto de rodovias dos países ao norte de América do Sul. Isso possibilitará: i) a utilização do Porto de Santana/AP por outros países, como a França, para intercâmbio comercial; ii) o uso dessa via para movimentação do grande potencial turístico regional e local; e iii) redução de problemas de infraestrutura para melhoramento do trânsito de mercadorias e pessoas.

Esta ponte representa o ponto de contato não somente entre dois países, de conexão entre duas cidades-gêmeas; também representa: o ponto de contato entre dois blocos econômicos (Mercosul/ União Européia); o ponto de conexão entre duas políticas de integração internacionais (IIRSA e INTERREG); a alternativa de mobilidade do comércio exterior da Guiana Francesa pelo Porto de Santana em relação ao porto guianense; a possibilidade de produtos industriais brasileiros se expandirem ao norte da América do Sul, em um espaço com moeda forte (o euro). Este é o único ponto da fronteira brasileira que possui tal característica, invertendo as relações transfronteiriças.

A fronteira também possui relações locais, informais, típicas do circuito inferior miltoniano. Mas o que mais chama atenção no processo de interação espacial entre Amapá e Guiana Francesa está na 
falta de informações comerciais oficiais entre esses dois espaços. Contudo, considerando a "inversão da fronteira" defendida por Porto (2010a e 2010b), há o comércio de produtos brasileiros na Guiana Francesa devido aos preços mais baratos no mercado macapaense. Assim, considerando que tem havido exportações de produtos pelo Amapá a Guiana Francesa (Circuito superior), mas sem o controle e acompanhamento de órgãos oficiais (Circuito inferior). Como configurar o circuito miltoniano para a fronteira Brasil/França?

Considerando, então a porosidade da fronteira em questão, a falta de acompanhamento e controle por órgãos oficiais, o mercado em expansão para o platô das Guianas pela Guiana Francesa e a sua efetivação comercial, dependendo do foco estabelecido, a fronteira Brasil/França ora se configura como um circuito inferior/superior, ora como superior/inferior. Ou seja, o entendimento de um circuito híbrido se deve à formatação de uma fronteira tardia assentada nas(os): expectativas de integração; ensaios de cooperação e; mudanças de relações fronteiriças para transfronteiriças, envolvendo o eixo Macapá [Brasil] - Caiena [Guiana Francesa].

\section{Considerações Finais}

Após o desmembramento do vizinho Estado do Pará em 1943, aconteceram várias reestruturações territoriais no Amapá, refletindo redefinições de seu uso territorial. Desde a justificativa de defesa nacional para a transfronteirização, a fronteira amapaense recebido investimentos e (re)inventado seu uso e sua função nas escalas econômicas envolvendo desde o local ao internacional, principalmente porque a medida que o espaço amapaense foi ocupado, transcendeu-se o pensar esta fronteira somente pelos assuntos militares. Ou seja, envolvem-se assuntos que perpassam a desestabilização interna causada por agentes externos; riscos oriundos de ordem não militar; os diversos graus de estabilidade democrática, o ambiente geo-estratégico que espaços fronteiriços se manifestam e se comportam e as conexões existentes e efetivas na/da fronteira.

Assim, considerando que o mundo de hoje se encontra conectado em rede, as ameaças externas são constantes, frequentes e invisíveis, à medida que essas conexões se efetivam, espaços são acionados, as fronteiras são inseridas por se integrarem às áreas de expansão de produtos industrializados, inventando-se novos espaços a serem ocupados, novos usos. As ameaças não são mais de conquista de território, mas de mercados. Não demarcam mais a espacialidade horizontal, mas vertical.

A nova configuração territorial amapaense, como uma fronteira tardia, implica em rever a sua condição fronteiriça, a sua atuação da defesa da faixa de fronteira e a sua inserção na economiamundo em função dos seguintes aspectos: a forte participação do capital estrangeiro na exploração de seus recursos naturais; a inserção de extensas áreas protegidas e preservadas nas discussões ambientais internacionais; na instalação de regimes aduaneiros especiais e; nas expectativas das obras do Programa de Aceleração do Crescimento do Governo Federal brasileiro e sua articulação com o IIRSA como parte integrante da configuração de um Brasil competitivo.

Assim sendo, a condição fronteiriça amapaense e a caracterização como fronteira tardia está diretamente ligada aos movimentos de (des)construção e (des)territorialização; à grande atuação do Estado, porém com fraca fiscalização; à criação/construção de próteses dos mais variados modelos; à nova configuração e intensidade de articulação das redes existentes como reflexos de cenários internacionais; às representatividades que a integração com a Guiana Francesa tem assumido para as escalas local e internacional da Amazônia Setentrional; à inserção amapaense no contexto das discussões ambientais internacionais e; a sua manutenção na economia-mundo como fornecedora de commodities e consumidora de produtos industrializados; vive-se expectativas de integração e constroem-se ensaios de cooperação, mas a interação espacial já está execução. Dinâmicas essas que vem desconstruindo velhas estruturas econômicas e sociais e reconstruindo com novos modelos e ritmos territoriais notadamente após o último decênio do século XX.

Por fim, esta fronteira possui um circuito híbrido de economia, ora como um circuito inferior/ superior, ora como superior/inferior, formatando-a como uma fronteira tardia assentada nas(os): 
expectativas de integração; ensaios de cooperação e; mudanças de relações fronteiriças para transfronteiriças, envolvendo o eixo Macapá [Brasil] - Caiena [Guiana Francesa]. Esta configuração tardia tem exigido novas criações e construções de políticas ambientais, diplomáticas, econômicas e de organização do território.

\section{Referências}

BRASIL. Ministério da Integração. Proposta de Reestruturação do Programa de Desenvolvimento da Faixa de Fronteira: Bases de uma política integrada de desenvolvimento regional para a faixa de fronteira. Ministério da Integração Nacional, Secretaria de Programas Regionais - Brasília, 2005.

BRASILEIRO, V. M. M. Plebiscito para a criação do Território Federal do Marajó. Câmara dos Deputados, Ago. 2003. Disponível em http://www2.camara.leg.br/documentos-e-pesquisa/publicacoes/estnottec/pdf/ 2003-568.pdf

BRITO, D. M. C. A construção do espaço público na gestão de unidades de conservação: o caso da APA do Rio Curiaú /AP. Macapá, 2003. 114 f. Dissertação (Mestrado em Desenvolvimento Sustentável)Universidade de Brasília, 2003. (Convênio com a Universidade Federal do Amapá).

BRUXELAS. Programa Operacional Amazônia 2007-2013: França - Guiana. MEMO/08/387, jun 2008.

CASTRO, M. L.; PORTO, J. L. R. Ponte Brasil-Guiana Francesa: os paradoxos da integração em um contexto multi-escalar. Oikos (Rio de Janeiro), v. 1, p. 51-75, 2007.

CAVALCANTI, M. Novas unidades da Federação - Redivisão territorial do país: uma necessidade. Senatus: Cadernos da Secretaria de Informação e Documentação, Brasília, v. 2, n. 1, p. 10, dez., 2002.

CE. Comissão Européia. Primeiro Fórum da ultraperiferia européia. Bruxelas, mai, 2010. Disponível em: ec.europa.eu/regional_policy/conferences/rup2010.

CEM - Conselho Empresarial da Madeira. Estudo sobre PME, Ultraperiferia e artigo 299o da Tratado da União Européia. Relatório Final. Fund Europa, fev 2005. Disponível em: www.aicopa.pt. Acesso em: 17 de abr de 2011.

CHELALA, C.; ANDRADE, E. B. de; PORTO, J. L. R. O pensamento ambiental e as modalidades de unidades de conservação no Amapá. Macapá, 2007. 15 p. (Mimeo.).

COUTO, M. E. A.; MELO, L. R. P.; MONTEIRO, R. M. G.; PORTO, J. L. R. Os ajustes espaciais e a expansão das redes geográficas: a inserção de próteses tecnológicas no espaço amapaense. Macapá, 2006. (Artigo vencedor do Colóquio de Iniciação Científica da Faculdade Seama, área Ciências Humanas)

FERREIRA FILHO, M. G. Curso de direito constitucional. 22 ed. São Paulo: Saraiva, 1975.

FORTUNA, M. A problemática das regiões ultraperiféricas. In: COSTA, J.S.; NIKAMP, P. Compêndio de Economia Regional. Cascais: Principia, 2009. Vol. 1.

FRANÇA. Coopération Territoriale Européenne 2007-2013. Programme de coopération. transfrontalière. Amazonie. Programme opérationnel. Document de travail. Version 17 Août 2007. Disponível em http:// www.cr-guyane.fr/ressources/File/e-services/POGuyane.pdf.

FREITAS, Aimberê. As políticas públicas e administrativas de Territórios Federais no Brasil. Boa Vista, 1991.

GRIMSON, A. Los processos de fronteirización: Flujos, redes e historicidad. In: Frontera Territorios y metáforas. Medelin: Hombre Nuevos Ed./INER/Universidad de Antioquia, 2003.

PORTO, J.L.R.; THEIS, I.M. Circuitos da Economia na fronteira amapaense: um híbrido de subsistemas para a sua reorganização espacial. Labor \& Engenho, Campinas [SP] Brasil, v.9, n.2, p.101-114, abr./jun. 2015.

$<$ http://www.conpadre.org $>$. 
HARVEY, D. O "novo imperialismo": ajustes espaço-temporais e acumulação por desapossamento. In: Revista Lutas Sociais. Vol. 13/14, $1^{\circ}$ sem. 2005a. Disponível em http://www.pucsp.br/neils/downloads/v13_14_harvey.pdf.

JACQUES, P. Curso de Direito Constitucional. Rio de Janeiro: Forense. 1977.

LIMA, R. A. P. Antropización, dinámicas de ocupación del territorio y desarrollo en la Amazonia brasileña: el caso del estado de Amapá. Bellaterra, 2004. 250 f. Tese (Doctorado en Geografía Humana)Universidad Autónoma de Barcelona, 2004.

LIMA, R. A.; PORTO, J. L. R. Ordenamento territorial amapaense: dinâmicas de um estado brasileiro na fronteira Amazônia. Trabalho apresentado no I SEMINÁRIO AMAZÔNIA E DESENVOLVIMENTO, em Macapá, em 12 de novembro de 2007. 27 p.

MAYER, L. R. A natureza jurídica dos Territórios Federais. Revista de Direito Administrativo. Rio de Janeiro, 125:15-41. Jul./set. 1976.

MEDEIROS, O. Territórios Federais: doutrina, legislação e jurisprudência. Rio de Janeiro: Nacional de Direito, 1944.

MEDEIROS, O. Administração Territorial (Comentários, subsídios e novas leis). Rio de Janeiro: Imprensa Nacional, 1946.

PINTO, M. J. S. O Fetiche do Emprego: um estudo sobre relações de trabalho de brasileiros na Guiana Francesa. 100. ed. São Paulo SP: EDITORA iGLU, 2011. 328p.

PORTO, Jadson Luís Rebelo. Amapá: Principais Transformações Econômicas e Institucionais - 1943 a 2000. Macapá: SETEC, 2003.

PORTO, J. L. R. A construção de condicionantes no espaço amapaense. In: PORTO, J. L. R.; CHELALA, C.; SILVA, G. V.; COUTO, M. E. A. Condicionantes construídos: reflexões sobre as transformações espaciais amapaenses. Macapá: Jadson Porto, 2007. (Série Percepções do Amapá, 5).

PORTO, J. L. R. A Condição Fronteiriça Amapaense: Da Defesa Nacional à Integração (Inter)Nacional. In: NASCIMENTO, Durbens. M. Amazônia e Defesa: dos fortes às novas conflitualidades. Belém (PA): (NAEA/ UFPa), 2010a.

PORTO, J. L. R. A Condição Periférico-Estratégica da Amazônia Setentrional: A Inserção do Amapá no Platô das Guianas. In: PORTO, Jadson Luís Rebelo; NASCIMENTO, Durbens Martins. Interações Fronteiriças no Platô das Guianas: novas construções, novas territorialidades /. Rio de Janeiro: Editora Publit, 2010b.

PORTO, J. L. R. Reinvenções do uso do território amapaense. In: SIMONIAN, L. T. L. (Org.). Políticas publicas, desenvolvimento, unidades de conservação e outras questões socioambientais no Amapá. 1 ed. Belém: NAEA/UFPA, 2010c, p. 91-113.

PORTO, J. L. R. Expectativas da Fronteira da Amazônia Setentrional: A busca pela interação do Platô das Guianas. In: PORTO, J. L. R.; NASCIMENTO, D. N. Dinâmicas Periférico-Estratégicas da Fronteira da Amazônia Setentrional: das políticas públicas e redes institucionais à integração espacial. Rio de Janeiro: Editora Publit, 2012.

PORTO, J. L. R.; COUTO, M. E. A.; BARROZO, J. M.; SANTOS, M. M.; THALEZ, G. M. Do Território Federal a Estado: Condicionantes para a execução de ajustes espaciais no Amapá - Brasil. In: BRASIL, W.; MIRTIL, E.; MACIEL, F. (Orgs.). 35 anos de colonização da Amazônia: Rondônia. Porto Velho: EDUFRO, 2007. p. 188-198.

PORTO, J. L. R.; LIMA, R. A. P.; BRITO, D. G. (Org.). Amapá: Aspectos de uma geografia em construção. Macapá: Jadson Porto, 2005. 90 p. (Série Percepções do Amapá, v. 1). 
PORTO, J. L. R.; MENDONÇA, M.; AZEVEDO, L. R.; ARAÚJO, M. W. R. Dilemas territoriais amapaenses: a (des)configuração de um estado em construção. In: Anais do XII Encontro de Geógrafos da América Latina. Montevidéu, 2009.

PORTO, J. L. R; SANTOS, P. G. S. Reconstrução da fronteira amapaense: da defesa aos novos usas da linde Amapá Guiana Francesa. In: SILVEIRA, E. D.; CAMARGO, S. A. F. De (Orgs.). Socioambientalismo de Fronteiras. 1ed.Curitiba: Juruá, 2012, v. 1, p. 101-112.

PORTO, J. L. R.; SILVA, G. V. novos usos e (re)construções da condição fronteiriça amapaense. In: Novos Cadernos NAEA. Belém, 12 (2): 253-297. Dez., 2009.

PORTO, J. L. R.; SUPERTI, E.; SILVA, G. V.; Novos usos do Território amapaense: Políticas públicas, desenvolvimento, ajustes espaciais na fronteira da Amazônia Setentrional. Macapá, datil. 2013.

PORTO, J. L. R.; SUPERTI, E.; TOSTES, J. A.; SOTTA, E. D. A Reformatação da fronteira amapaense: das políticas públicas aos planos diretores e ambientais. In: PORTO, J. L. R.; SOTTA, E. D.. Reformatações Fronteiriças no Platô das Guianas: (re)territorialidades de cooperações em construção. Rio de Janeiro: Publit, 2011.

PROENÇA Jr. Domício. Evolução do Pensamento Brasileiro em Matéria de Defesa e Segurança - Uma Estratégia Para o Brasil. In: PINTO, J.R.; ALMEIDA, A.J; ROCHA, R.; R; SILVA. D. P. (Orgs.): Reflexões sobre defesa e segurança: uma estratégia para o Brasil. Brasília: Ministério da Defesa, Secretaria de Estudos e de Cooperação, 2004.

REIS, A. C. F. Território do Amapá: perfil histórico. Rio de Janeiro: Imprensa Nacional, 1949.

SANTOS, M. O retorno do território? In: SANTOS, M. et al (orgs). Território: globalização e fragmentação. 2. ed. São Paulo: HUCITEC, 1994.p. 15-20.

SANTOS, M. Metamorfoses do espaço habitado. São Paulo: Hucitec, 1997.

SANTOS, M. A natureza do espaço: Técnica e tempo. Razão e emoção. São Paulo: Hucitec, 1996.

SANTOS, M. 0 espaço dividido: Os dois circuitos da economia urbana dos países subdesenvolvidos. 2a ed. São Paulo: Edusp, 2004.

SAQUET, M. A. Os tempos e os territórios da Colonização italiana. Porto Alegre: EST edições, 2002.

SILVA, G. V. Usos contemporâneos da fronteira franco-brasileira: entre os ditames globais e a articulação local. Porto Alegre, 2008. 180 f., il., anexos. Dissertação (Mestrado em Geografia)-Universidade Federal do Rio Grande do Sul, 2008.

SILVA, G.V. Uma nova página na geopolítica franco-brasileira: As expectativas que emergem com a cooperação transfronteiriça entre a Guiana Francesa e o Estado do Amapá no século XXI. UFRJ/PPGGEO, Rio de Janeiro, 2013. (Tese de doutorado). Orientadora: Lia Osório Machado. Coorientador: Jadson Luis Rebelo Porto.

SILVA, G.V.; PORTO, J.L.R. 0 comércio internacional do Estado do Amapá: condições, construções e adaptações. Apresentado no XV Encontro Nacional de Estudantes de Geografia - ENEG. Salvador [BA], 2005.

SOUZA, M. A. A. 0 Retorno do território. In: OSAL - Observatório Social de América Latina. 6 (16): 251261, jan./abr.. 2005. Buenos Ayres. CLACSO.

SUPERTI. E. Políticas públicas e integração sul americana das fronteiras internacionais da Amazônia brasileira. Novos Cadernos Naea, v. 2, n.14, 2011, p.32-48.

TEMER, Michel. Território Federal nas constituições brasileiras. São Paulo: Revista dos Tribunais/ EDUC, 1975. 